\title{
Asthma, airflow limitation and mortality risk in the general population
}

\author{
Shuang Huang ${ }^{1,2}$, Monica M. Vasquez ${ }^{1,2}$, Marilyn Halonen ${ }^{1}$, \\ Fernando D. Martinez ${ }^{1}$ and Stefano Guerra ${ }^{1,3}$
}

Affiliations: ${ }^{1}$ Arizona Respiratory Center, University of Arizona, Tucson, AZ, USA. ${ }^{2}$ Mel and Enid Zuckerman College of Public Health, University of Arizona, Tucson, AZ, USA. ${ }^{3}$ CREAL Centre, CIBERESP, Universitat Pompeu Fabra, Barcelona, Spain.

Correspondence: Stefano Guerra, Arizona Respiratory Center, University of Arizona, 1501 N Campbell Ave, Tucson, AZ 85724-5030, USA. E-mail: stefanodemail.arizona.edu

ABSTRACT Asthma and chronic obstructive pulmonary disease co-exist in a significant proportion of patients. Whether asthma increases mortality risk among subjects with airflow limitation remains controversial.

We used data from 2121 adult participants in the population-based Tucson Epidemiological Study of Airway Obstructive Disease cohort. At enrolment (1972-1973), participants completed questionnaires and lung function tests. Participants were categorised into four groups based on the combination of airflow limitation (AL; forced expiratory volume in $1 \mathrm{~s}$ (FEV1)/forced vital capacity (FVC) $<70 \%$ ) and physicianconfirmed asthma at baseline. Vital status as of January 2011 was assessed through the National Death Index. Cox proportional hazards models were used to test differences in mortality risk across the four airflow limitation/asthma groups.

In multivariate Cox models, the AL+/asthma+ group had a $114 \%$ increased mortality risk during followup compared with the AL-/asthma- group (adjusted HR 2.14; 95\% CI 1.64-2.79). The corresponding hazard ratios were 1.09 (95\% CI $0.89-1.34$ ) and 1.34 (95\% CI 1.14-1.57) for the AL-/asthma+ and AL +/asthma- groups, respectively. Among subjects with airflow limitation, asthma was associated with increased mortality risk (HR 1.58, 95\% CI 1.17-2.12). However, this increased risk was substantially reduced and no longer significant after further adjustment for baseline FEV1 levels. Similar results were obtained when airflow limitation was defined as FEV1/FVC less than the lower limit of normal.

In a population-based cohort, subjects with concomitant airflow limitation and asthma had an increased risk of dying, which was mainly related to their baseline lung function deficits.

@ERSpublications

Asthma increases mortality risk in the general population, but only when associated with lung function deficits http://ow.ly/CckiC

This article has supplementary material available from erj.ersjournals.com

Received: June 142014 | Accepted after revision: Sept 072014 | First published online: Oct 162014

Support statement: This study was supported by awards from the National Heart, Lung, and Blood Institute, Bethesda, MD, USA (HL107188 and HL095021).

Conflict of interest: Disclosures can be found alongside the online version of this article at erj.ersjournals.com

Copyright OERS 2015 


\section{Introduction}

Asthma and chronic obstructive pulmonary disease (COPD) are highly prevalent obstructive lung diseases that have partially distinct risk factors and clinical manifestations, although they sometimes co-exist in the same patients [1-3]. Chronic airflow limitation is the hallmark of COPD [4]. At the population level asthma has been shown to be a major risk factor for persistent airflow limitation [5] and to be a co-existing condition in up to $55 \%$ of cases of non-fully reversible airflow limitation [6]. In this framework, the asthma-COPD overlap syndrome has been gaining increasing attention as a condition that may have unique characteristics and require targeted disease management $[7,8]$.

A growing body of evidence indicates that cases with co-existing asthma and COPD have higher healthcare costs [9-11] and higher degrees of disease severity $[12,13]$ than patients with either disease alone. In the COPDGene study [13], as compared with patients with COPD alone, those with both COPD and asthma were more likely to experience frequent disease exacerbations, which in turn are known to be related to worse quality of life and higher mortality risk $[14,15]$. In line with these observations, asthma phenotypes, such as asthma attacks with eosinophilia [16] and bronchial hyperresponsiveness [17], have been associated with an increased risk of mortality from COPD. Conversely, the presence of airflow limitation or a concomitant diagnosis of COPD has been found to increase mortality risk among patients with asthma [18-21]. In a population-based study [22], the combined presence of self-reported doctor-diagnosed asthma and COPD was associated with mortality rates that were higher than those associated with either disease alone. However, in apparent contrast with the studies above, several reports that identified patients from healthcare databases through previous COPD-related hospitalisations or medication use found the presence of concomitant asthma to be associated with no significant effects on, or even with protection against, mortality risk [23-26].

The above discrepancies may be related to the use of population-based versus clinical cohorts, with the latter being more likely to include moderate to severe forms of disease and, in turn, less representation of the entire population of subjects with chronic airway obstruction. The aim of our study was to use the population-based Tucson Epidemiological Study of Airway Obstructive Disease (TESAOD) to determine the combined effects of asthma and airflow limitation (defined as a low forced expiratory volume in $1 \mathrm{~s}$ $\left(\mathrm{FEV}_{1}\right) /$ forced vital capacity (FVC) ratio) on all-cause mortality risk over nearly 40 years of follow-up.

\section{Methods}

Study population and vital status

TESAOD is a population-based prospective cohort study on non-Hispanic white households initiated in Tucson (AZ, USA) in 1972. Details of the enrolment process have been reported previously [27]. At enrolment, TESAOD participants completed both a standardised respiratory questionnaire and spirometric lung function tests according to methods previously described [28]. 12 additional follow-up surveys were completed approximately every 2 years up to 1996 and the vital status of TESAOD participants was updated through contact with family and designated next-of-kin, and collection of death certificates. In 2013, a review of vital status as of January 1, 2011 for the TESAOD cohort was completed through linkage with the National Death Index [29]. Causes of death were determined based on death certificates for events that occurred up to 1978 and based on National Death Index records for events that occurred after 1978.

\section{Baseline phenotype variables}

Doctor-diagnosed asthma (hereafter referred to simply as asthma) was defined as a positive report in the enrolment survey that the participant was told by a doctor that he or she had asthma. Years of formal education, smoking status and number of pack-years were assessed at baseline based on questionnaire information.

Consistent with previous TESAOD studies, percentage predicted values for spirometric indices were computed using reference equations generated in the same population by KNUDSON et al. [30] and lower limit of normal (LLN) equations were derived from HankInson et al. [31]. In this study, we used two definitions of airflow limitation at baseline based on a FEV1/FVC ratio either $<70 \%$ or below the sex- and age-specific LLN threshold. Low FEV1 was defined as FEV $1<80 \%$ of the predicted value.

At the time of the spirometric test, study nurses measured participants' weight and height. Body mass index (BMI) was computed and BMI categories were defined as underweight $\left(<18.5 \mathrm{~kg} \cdot \mathrm{m}^{-2}\right)$, normal weight $\left(\geqslant 18.5-25 \mathrm{~kg} \cdot \mathrm{m}^{-2}\right)$, overweight $\left(\geqslant 25-30 \mathrm{~kg} \cdot \mathrm{m}^{-2}\right)$, and obese $\left(\geqslant 30 \mathrm{~kg} \cdot \mathrm{m}^{-2}\right)$.

Skin-prick tests for allergens common in the Tucson area (house dust, Bermuda grass, tree mix, weed mix and Dematiaceae mould mix) were completed at the baseline survey and positive skin-prick tests were defined as a wheal $\geqslant 3 \mathrm{~mm}$ larger than the control wheal for at least one tested allergen. 


\section{Eosinophilia and serum IgE}

Blood samples were collected at enrolment. Eosinophils were measured as percentages from stained slides and blood eosinophilia was defined as eosinophils $>4 \%$. Measurements of serum total IgE were carried out in duplicate according to the paper radioimmunosorbent test (Pharmacia Diagnostics, Piscataway, NJ, USA) method.

\section{Statistical analyses}

For main analyses, we categorised subjects into four mutually exclusive groups defined by the combination of airflow limitation and asthma status at baseline (airflow limitation/asthma: $-/-,-/+,+/-$ and $+/+$ ). This process was repeated for each of the two definitions of airflow limitation. For secondary analyses, to evaluate the impact that the combination of low FEV1 and asthma had on mortality risk, four mutually exclusive groups were also generated based on the combination of $\mathrm{FEV} 1<80 \%$ predicted and asthma status at baseline.

ANOVA and Chi-squared tests were used to compare baseline characteristics across the four groups. IgE levels were log-transformed to achieve normality. Cox proportional hazards models were used to investigate the association between the airflow limitation/asthma groups and all-cause mortality. In these models, the starting date was the date of completion of the baseline survey and the end date was the date of death if the subject was deceased or January 1, 2011 if the subject was still alive as of that date. Cause-specific mortality was analysed in secondary analyses for the three most common causes of death: heart disease, COPD and cancer. For these analyses we used competing risk models [32], and results were also confirmed using Cox models with death events due to causes other than the specific cause of interest treated as censored observations. In all analyses, household-clustered sandwich estimators of standard errors were used. Three subjects with missing smoking status and/or pack-year information were excluded from Cox models. 74 subjects with missing BMI information were categorised into a BMI "missing" category. 392 subjects with missing eosinophilia information were categorised into an eosinophilia "missing" category so that they could be included in Cox models in sensitivity analyses (table E1).

\section{Results}

\section{Baseline characteristics}

At baseline, 2495 non-Hispanic white TESAOD participants were aged 21-80 years. Of these, 2121 (85\%) participants completed both questionnaire and lung function tests and were included in the present study. As compared with the 374 subjects with incomplete information, the 2121 subjects included in this study did not differ significantly in terms of sex, age, education, BMI, smoking, or mortality rates during the follow-up.

Tables 1 and 2 show the baseline characteristics of participants across the four groups defined by the combination of airflow limitation and asthma. When airflow limitation was defined as FEV1/FVC $<70 \%$ (table 1), 78\% of participants had neither airflow limitation nor asthma, $8 \%$ had asthma only, $11 \%$ had airflow limitation only, and 3\% had both. Similar percentages were found when airflow limitation was defined as FEV1/FVC less than the LLN (table 2). Thus, asthma occurred in $24 \%$ of subjects with airflow limitation and airflow limitation was present in $31 \%$ of cases of asthma at the population level.

When airflow limitation was defined as FEV1/FVC $<70 \%$ (table 1), male sex, older age and lower education were associated with the presence of airflow limitation with or without asthma. In contrast, being overweight or obese was associated with asthma, independent of the concomitant presence of airflow limitation. The highest percentage of current smokers was found in the group with airflow limitation only and, among smokers, the two groups with airflow limitation had higher pack-years than the two groups without airflow limitation. High percentages of positive skin-prick tests and high serum IgE levels were found in the two groups with asthma. The group with both airflow limitation and asthma had the highest percentage of eosinophilia and, of note, the lowest FEV1 levels.

When airflow limitation was defined as FEV1/FVC less than the LLN (table 2), similar trends were found across the four groups, but sex distribution was not significantly different anymore and age differences were reduced in magnitude.

\section{The relationship of airflow limitation and asthma to all-cause mortality}

As of January 2011, 1367 (64\%) of the 2121 participants had died. Participants in the two groups with airflow limitation had the highest percentages of mortality (tables 1 and 2). After adjusting for age, sex, education, BMI, smoking status and pack-years, the two groups with airflow limitation still had a significantly higher mortality risk than subjects with no airflow limitation and no asthma (table 3 ). This increased risk was greater in the group with both airflow limitation and asthma. When airflow limitation was defined as FEV1/FVC $<70 \%$ (model 1), compared with subjects with no airflow limitation and no 
TABLE 1 Baseline characteristics of participants across the four groups of airflow limitation $(\mathrm{AL})^{\#}$ and asthma

\begin{tabular}{|c|c|c|c|c|c|c|}
\hline & Total & $\begin{array}{c}\mathrm{AL}-/ \\
\text { asthma- }\end{array}$ & $\begin{array}{c}\mathrm{AL}-/ \\
\text { asthma+ }\end{array}$ & $\begin{array}{c}\mathrm{AL+l} \\
\text { asthma- }\end{array}$ & $\begin{array}{c}\mathrm{AL}+/ \\
\text { asthma+ }\end{array}$ & p-value \\
\hline Subjects & $2121(100)$ & 1645 (78) & $165(8)$ & $237(11)$ & 74 (3) & \\
\hline Males & 925 (44) & $692(42)$ & $66(40)$ & $124(52)$ & $43(58)$ & 0.001 \\
\hline Age years & $50 \pm 18$ & $49 \pm 18$ & $46 \pm 18$ & $60 \pm 15$ & $59 \pm 14$ & $<0.001$ \\
\hline $\mathrm{BMI}^{+}$ & & & & & & 0.001 \\
\hline Normal $18.5-25 \mathrm{~kg} \cdot \mathrm{m}^{-2}$ & $1140(56)$ & 902 (57) & $76(48)$ & 129 (57) & $33(45)$ & \\
\hline Underweight $<18.5 \mathrm{~kg} \cdot \mathrm{m}^{-2}$ & $60(3)$ & $42(3)$ & $1(1)$ & $14(6)$ & $3(4)$ & \\
\hline Overweight $25-30 \mathrm{~kg} \cdot \mathrm{m}^{-2}$ & $694(34)$ & 532 (33) & 60 (38) & $69(31)$ & $33(45)$ & \\
\hline Obese $\geqslant 30 \mathrm{~kg} \cdot \mathrm{m}^{-2}$ & $153(7)$ & $114(7)$ & $21(13)$ & $14(6)$ & $4(5)$ & \\
\hline Education for $>12$ years & 913 (43) & $733(45)$ & $78(47)$ & 78 (33) & 24 (32) & 0.001 \\
\hline Smoking status ${ }^{\S}$ & & & & & & $<0.001$ \\
\hline Never-smoker & $868(41)$ & $737(45)$ & 64 (39) & 45 (19) & $22(30)$ & \\
\hline Former smoker & $519(24)$ & $357(22)$ & $45(27)$ & $85(36)$ & $32(43)$ & \\
\hline Current smoker & 733 (35) & 550 (33) & 56 (34) & 107 (45) & 20 (27) & \\
\hline Pack-years $f$ & $26 \pm 24$ & $23 \pm 21$ & $21 \pm 22$ & $40 \pm 28$ & $39 \pm 29$ & $<0.001$ \\
\hline FEV $1 \%$ predicted & $93 \pm 20$ & $98 \pm 17$ & $89 \pm 17$ & $73 \pm 22$ & $59 \pm 24$ & $<0.001$ \\
\hline Positive skin-prick tests"\# & $744(36)$ & 552 (34) & $101(64)$ & $61(26)$ & $30(43)$ & $<0.001$ \\
\hline Eosinophilia ศก & $135(8)$ & $86(7)$ & $18(14)$ & $17(9)$ & $14(23)$ & $<0.001$ \\
\hline $\lg E \mathrm{IU} \cdot \mathrm{mL}^{-1++}$ & $28(26-30)$ & $24(22-26)$ & $86(66-111)$ & $27(21-33)$ & $82(54-125)$ & $<0.001$ \\
\hline Self-reported COPD ${ }^{\S \S}$ & $318(15)$ & $143(9)$ & $57(35)$ & $69(30)$ & $49(66)$ & $<0.001$ \\
\hline Deceased by January 1, 2011 & $1367(64)$ & $994(60)$ & 97 (59) & 209 (88) & 67 (91) & $<0.001$ \\
\hline
\end{tabular}

Data are presented as $\mathrm{n}(\%)$, mean \pm SD or geometric mean (95\% confidence interval), unless otherwise stated. BMI: body mass index; FEV1: forced expiratory volume in $1 \mathrm{~s}$; COPD: chronic obstructive pulmonary disease. ": defined as FEV $1 /$ forced vital capacity $<70 \%$; ": $p$-values are from ANOVA for continuous variables or Pearson Chi-squared test for categorical variables across the four groups; $+: n=2047$; §: $n=2120 ;{ }^{f}$ : only calculated among 1250 smokers; ${ }^{\# \#}: n=2084 ;{ }^{\Uparrow 1}: n=1600 ;{ }^{++}: n=1903 ;{ }^{\S \S}$ : defined as a self-report of having been seen by a doctor for chronic bronchitis and/or emphysema ( $n=2111)$.

asthma, the group with airflow limitation only had a $34 \%$ increase and the group with both airflow limitation and asthma a $114 \%$ increase in all-cause mortality risk. When the two groups were compared with each other, the risk associated with the presence of both airflow limitation and asthma was significantly higher than that associated with the presence of airflow limitation only (adjusted HR 1.60, 95\% CI 1.19-2.14). In contrast, the presence of asthma only (i.e. without airflow limitation) was not associated with an increased mortality risk (adjusted HR 1.09, nonsignificant). Similar results were found when airflow limitation was defined as FEV1/FVC less than the LLN (model 2). After full adjustment, significant increases by $37 \%$ and $135 \%$ in mortality risk were found for the group with airflow limitation only and for the group with both airflow limitation and asthma, respectively.

Additional inclusion of total serum IgE and eosinophilia as covariates in the models did not modify the increased risk of mortality associated with the group with combined airflow limitation and asthma (table E1). However, when combination groups were based on FEV1 \% predicted and asthma (tables E2 and E3), the groups with $\mathrm{FEV} 1<80 \%$ predicted showed similar mortality risks independent of whether they had or did not have asthma. These results suggest that the increased mortality risk seen among subjects with airflow limitation and asthma may be related to the lower FEV1 levels shown by this group.

\section{Effects of asthma on mortality risk among subjects with airflow limitation}

To test the above hypothesis and better characterise the effects of asthma on mortality risk among subjects with airflow limitation, we restricted Cox proportional hazards models to the 310 participants with FEV1/ FVC $<70 \%$ (table 4) and to the 291 participants with FEV1/FVC less than the LLN (table 5) at baseline and tested the effects of asthma with and without concomitant adjustment for baseline FEVi levels. After adjusting for sex, age, BMI, education, smoking status and pack-years, asthma was significantly associated with a 58\% (adjusted HR 1.58, 95\% CI 1.17-2.12) and a 64\% (adjusted HR 1.64, 95\% CI 1.18-2.29) increased mortality risk among subjects with FEV1/FVC $<70 \%$ and subjects with FEV1/FVC less than the LLN, respectively (model 1 in tables 4 and 5). However when Cox proportional hazards models were further adjusted for baseline levels of $\mathrm{FEV}_{1} \%$ predicted, the association of asthma with mortality was reduced by $>50 \%$ and was no longer significant (model 2 in tables 4 and 5). These results suggest that 
TABLE 2 Baseline characteristics of participants across the four groups of airflow limitation $(\mathrm{AL})^{\#}$ and asthma

\begin{tabular}{|c|c|c|c|c|c|c|}
\hline & Total & $\begin{array}{c}\mathrm{AL}-\mathrm{I} \\
\text { asthma- }\end{array}$ & $\begin{array}{c}\mathrm{AL}-/ \\
\text { asthma+ }\end{array}$ & $\begin{array}{c}\mathrm{AL+}+ \\
\text { asthma- }\end{array}$ & $\begin{array}{c}\mathrm{AL+}+ \\
\text { asthma+ }\end{array}$ & p-value ${ }^{\pi}$ \\
\hline Subjects & $2121(100)$ & $1667(79)$ & $163(8)$ & $215(10)$ & $76(4)$ & \\
\hline Males & 925 (44) & 717 (43) & $67(41)$ & $99(46)$ & $42(55)$ & 0.146 \\
\hline Age years & $50 \pm 18$ & $49 \pm 18$ & $48 \pm 18$ & $54 \pm 18$ & $55 \pm 17$ & $<0.001$ \\
\hline $\mathrm{BMI}^{+}$ & & & & & & $<0.001$ \\
\hline Normal $18.5-25 \mathrm{~kg} \cdot \mathrm{m}^{-2}$ & $1140(56)$ & $905(56)$ & $72(46)$ & $126(63)$ & 37 (49) & \\
\hline Underweight $<18.5 \mathrm{~kg} \cdot \mathrm{m}^{-2}$ & $60(3)$ & $42(3)$ & $1(1)$ & $14(7)$ & $3(4)$ & \\
\hline Overweight $25-30 \mathrm{~kg} \cdot \mathrm{m}^{-2}$ & $694(34)$ & $551(34)$ & $66(42)$ & $50(25)$ & $27(36)$ & \\
\hline Obese $\geqslant 30 \mathrm{~kg} \cdot \mathrm{m}^{-2}$ & $153(7)$ & $117(7)$ & $17(11)$ & $11(5)$ & $8(11)$ & \\
\hline Education for $>12$ years & $913(43)$ & $738(44)$ & $73(45)$ & $73(34)$ & $29(38)$ & 0.027 \\
\hline Smoking status ${ }^{\S}$ & & & & & & $<0.001$ \\
\hline Never-smoker & $868(41)$ & $746(45)$ & $65(40)$ & $36(17)$ & $21(28)$ & \\
\hline Former smoker & $519(24)$ & $374(22)$ & $46(28)$ & $68(32)$ & $31(41)$ & \\
\hline Current smoker & 733 (35) & 546 (33) & 52 (32) & $111(52)$ & $24(32)$ & \\
\hline Pack-years $f$ & $26 \pm 24$ & $24 \pm 22$ & $24 \pm 23$ & $35 \pm 28$ & $33 \pm 29$ & $<0.001$ \\
\hline FEV $1 \%$ predicted & $93 \pm 20$ & $98 \pm 17$ & $89 \pm 17$ & $72 \pm 22$ & $60 \pm 24$ & $<0.001$ \\
\hline Positive skin-prick tests $\# \#$ & $744(36)$ & 544 (33) & $99(63)$ & $69(32)$ & $32(44)$ & $<0.001$ \\
\hline Eosinophilia ศก & $135(8)$ & $87(7)$ & $17(14)$ & $16(10)$ & $15(24)$ & $<0.001$ \\
\hline $\lg E \mathrm{IU} \cdot \mathrm{mL}^{-1++}$ & $28(26-30)$ & $23(21-25)$ & 83 (64-108) & $30(24-38)$ & $87(58-132)$ & $<0.001$ \\
\hline Self-reported COPD $D^{\S \S}$ & $318(15)$ & $146(9)$ & $55(34)$ & $66(31)$ & $51(67)$ & $<0.001$ \\
\hline Deceased by January 1, 2011 & $1367(64)$ & $1037(62)$ & $103(63)$ & $166(77)$ & $61(80)$ & $<0.001$ \\
\hline
\end{tabular}

Data are presented as $\mathrm{n}(\%)$, mean \pm SD or geometric mean (95\% confidence interval), unless otherwise stated. $\mathrm{BMI}$ : body mass index; FEV1: forced expiratory volume in $1 \mathrm{~s}$; COPD: chronic obstructive pulmonary disease. \#: defined as FEV1/forced vital capacity less than the lower limit of normal; " ${ }^{\text {: }}$ p-values are from ANOVA for continuous variables or Pearson Chi-squared test for categorical variables across the four groups; $+: n=2047$;

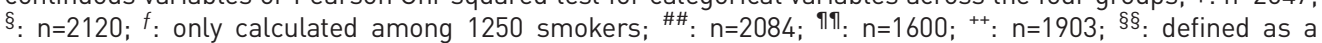
self-report of having been seen by a doctor for chronic bronchitis and/or emphysema ( $n=2111)$.

lung function deficits explained a large proportion of the increased mortality risk associated with asthma. In line with this scenario, among subjects with baseline $\mathrm{FEV} 1<80 \%$ predicted no asthma effects were found on mortality risk (table E3) and, among subjects with airflow limitation at baseline, COPD was the only leading cause of death that was increased by the presence of a concomitant asthma diagnosis at baseline (table E4 and fig. 1).

\section{Discussion}

In this study we found that, in a cohort representative of the general adult population, the co-existence of airflow limitation and asthma doubled the risk of dying during follow-up, but these effects were mainly related to the baseline lung function deficits of this group.

Asthmatics that develop airflow limitation and/or chronic lung function deficits have long been known to be at increased risk of dying [18-21]. In a Danish cohort of $>1000$ outpatients with asthma, having a FEV 1 $<70 \%$ predicted increased the risk of dying during the study follow-up by several fold [20]. Similarly, a $10 \%$ increase in baseline $\mathrm{FEV}_{1} \%$ predicted was associated with a $>20 \%$ reduction in mortality risk in a group of 89 patients with chronic asthma followed for 17 years [33]. Therefore, it is not surprising that in our study we found a mortality risk twice as high in subjects with asthma and airflow limitation than in subjects with asthma alone.

Nonetheless, whether the presence of asthma increases the risk of dying among subjects with COPD remains controversial. Using data from the National Health and Nutrition Examination Survey III, Diaz-GuzMAn et al. [22] found that, compared to participants who did not report either asthma or COPD, those with COPD alone had a $44 \%$ increased risk of dying but those with both COPD and asthma had an $83 \%$ increased risk of dying, suggesting stronger effects on mortality for the latter group. In contrast, several studies that selected patients with COPD based on healthcare databases and records of hospitalisations and/or treatment did not find increased mortality effects [23], or even reported protective effects [24-26], of a concomitant asthma diagnosis. A possible explanation for these apparently conflicting findings is that co-existing asthma represents a marker of poor prognosis among subjects with airflow limitation in the general population but not necessarily in selected clinical cohorts of COPD patients, 


\begin{tabular}{|c|c|c|}
\hline & Model $1^{\pi}$ & Model $2^{+}$ \\
\hline \multicolumn{3}{|l|}{ Sex } \\
\hline Male & 1 & 1 \\
\hline Female & $0.73(0.65-0.82)^{* * *}$ & $0.73(0.65-0.82)^{* * *}$ \\
\hline Age at baseline years & $1.11(1.10-1.11)^{* * *}$ & $1.11(1.10-1.12)^{* * *}$ \\
\hline \multicolumn{3}{|l|}{ BMI } \\
\hline Normal $18.5-25 \mathrm{~kg} \cdot \mathrm{m}^{-2}$ & 1 & 1 \\
\hline Underweight $<18.5 \mathrm{~kg} \cdot \mathrm{m}^{-2}$ & $1.71(1.17-2.48)^{*}$ & $1.69(1.16-2.47)^{*}$ \\
\hline Overweight $25-30 \mathrm{~kg} \cdot \mathrm{m}^{-2}$ & $0.91(0.81-1.02)$ & $0.91(0.81-1.02)$ \\
\hline Obese $\geqslant 30 \mathrm{~kg} \cdot \mathrm{m}^{-2}$ & $1.32(1.09-1.59)^{*}$ & $1.31(1.08-1.58)^{*}$ \\
\hline Education for $>12$ years & $0.90(0.81-1.00)^{*}$ & $0.90(0.81-1.00)^{*}$ \\
\hline \multicolumn{3}{|l|}{ Smoking status } \\
\hline Never-smoker & 1 & 1 \\
\hline Former smoker & $0.89(0.76-1.05)$ & $0.89(0.76-1.04)$ \\
\hline Current smoker & $1.42(1.21-1.67)^{* * *}$ & $1.41(1.20-1.66)^{* * *}$ \\
\hline Pack-years & $1.01(1.01-1.01)^{* * *}$ & $1.01(1.01-1.01)^{* * *}$ \\
\hline $\mathrm{AL}$-/asthma- & 1 & 1 \\
\hline $\mathrm{AL}-$ /asthma+ & 1.09 (0.89-1.34) & $1.08(0.89-1.31)$ \\
\hline $\mathrm{AL}+$ /asthma- & $1.34(1.14-1.57)^{* * *}$ & $1.37(1.14-1.63)^{*}$ \\
\hline $\mathrm{AL}+$ /asthma+ & $2.14(1.64-2.79)^{* * *}$ & $2.35(1.77-3.11)^{* * *}$ \\
\hline $\begin{array}{l}\text { Data are presented as hazar } \\
{ }^{\#}: \mathrm{n}=2118 ;{ }^{\uparrow} \text { : based on the } \\
\text { vital capacity (FVC) }<70 \%{ }^{+} \text {: } \\
\text { limit of normal. }{ }^{*}: p<0.05 \text {; }^{* *}\end{array}$ & $\begin{array}{l}\text { ence interval). BMI: } \\
\text { limitation as forced } \\
\text { ition of airflow limit }\end{array}$ & $\begin{array}{l}\text { L: airflow limitation. } \\
\text { in } 1 \mathrm{~s}(\mathrm{FEV} 1) / \text { forced } \\
\text { less than the lower }\end{array}$ \\
\hline
\end{tabular}

TABLE 4 Cox proportional hazards models for all-cause mortality among the 310 subjects with airflow limitation $(\mathrm{AL})$ at baseline ${ }^{\#}$

Sex

Male

Female

Age at baseline years

BMI

Normal $18.5-25 \mathrm{~kg} \cdot \mathrm{m}^{-2}$

Underweight $<18.5 \mathrm{~kg} \cdot \mathrm{m}^{-2}$

Overweight $25-30 \mathrm{~kg} \cdot \mathrm{m}^{-2}$

Obese $\geqslant 30 \mathrm{~kg} \cdot \mathrm{m}^{-2}$

Education for $>12$ years

Smoking status

Never-smoker

Former smoker

Current smoker

Pack-years

AL/asthma groups

$\mathrm{AL}+$ /asthma-

$\mathrm{AL}+$ /asthma+

FEV $1 \%$ predicted at baseline
Model $1^{\pi}$

1

Model $2^{+}$

$0.66(0.50-0.87) *$

$1.10(1.08-1.12)^{* * *}$

$2.29(1.29-4.06)^{*}$

$0.71(0.54-0.93) *$

$1.09(0.61-1.96)$

$0.76(0.59-0.98) *$

1

$0.99(0.66-1.48)$

$1.27(0.83-1.92)$

$1.01(1.00-1.02)^{* * *}$

1

$1.58(1.17-2.12)^{* * *}$
1

$0.72(0.55-0.95) *$

$1.10(1.09-1.12)^{* * *}$

1

$2.27(1.27-4.07)^{*}$

$0.79(0.61-1.03)$

$1.04(0.56-1.93)$

0.80 (0.62-1.03)

1

$1.01(0.67-1.52)$

$1.29(0.86-1.94)$

$1.01(1.00-1.01)^{*}$

$1.27(0.94-1.73)$

$0.98(0.98-0.99)^{* * *}$

Data are presented as hazard ratio (95\% confidence interval). BMI: body mass index; $F E V_{1}$ : forced expiratory volume in $1 \mathrm{~s}$. \# : defined as $\mathrm{FEV}_{1} /$ forced vital capacity $<70 \%$; ${ }^{\text {? }}$ : included sex, age, BMI, education, smoking status, pack-years and asthma; ${ }^{+}$: further adjusted for $\mathrm{FEV} 1 \%$ predicted. ${ }^{*}: \mathrm{p}<0.05 ;{ }^{* * *}$ : $\mathrm{p}<0.001$.

which are likely to represent the group of patients with the most severe forms of airflow limitation. At least three observations are consistent with this scenario. First, previous reports from the TESAOD study found decreased rather than increased mortality risk associated with asthma when analyses were restricted 
TABLE 5 Cox proportional hazards models for all-cause mortality among the 291 subjects with airflow limitation $(\mathrm{AL})$ at baseline ${ }^{\#}$

Model $1^{\text {n }}$

\begin{tabular}{lcc}
\hline Sex & & 1 \\
Male & 1 & 1 \\
Female & $0.73(0.54-0.99)^{*}$ & $0.81(0.60-1.10)$ \\
Age at baseline years & $1.10(1.08-1.11)^{* * *}$ & $1.10(1.08-1.11)^{* * *}$ \\
BMI & 1 & 1 \\
$\quad$ Normal $18.5-25 \mathrm{~kg} \cdot \mathrm{m}^{-2}$ & $2.48(1.29-4.74)^{*}$ & $2.46(1.30-4.65)^{*}$ \\
Underweight $<18.5 \mathrm{~kg} \cdot \mathrm{m}^{-2}$ & $0.73(0.53-1.00)^{*}$ & $0.80(0.60-1.09)$ \\
Overweight $25-30 \mathrm{~kg} \cdot \mathrm{m}^{-2}$ & $0.96(0.50-1.83)$ & $0.93(0.47-1.84)$ \\
Obese $\geqslant 30 \mathrm{~kg} \cdot \mathrm{m}^{-2}$ & $0.70(0.53-0.92)^{*}$ & $0.71(0.53-0.94)^{*}$ \\
Education for $>12$ years & & 1 \\
Smoking status & 1 & $1.15(0.73-1.83)$ \\
$\quad$ Never-smoker & $1.10(0.70-1.71)$ & $1.36(0.85-2.20)$ \\
Former smoker & $1.22(0.77-1.94)$ & $1.01(1.00-1.02)^{*}$ \\
Current smoker & $1.01(1.00-1.02)^{*}$ & 1 \\
Pack-years & & $1.30(0.91-1.84)$ \\
AL/asthma groups & 1 & $0.98(0.97-0.99)^{* * *}$ \\
AL+/asthma- & $1.64(1.18-2.29)^{*}$ & \\
AL+/asthma+ & & \\
FEV1 \% predicted at baseline & & \\
\end{tabular}

Data are presented as hazard ratio (95\% confidence interval). BMI: body mass index; FEV1: forced expiratory volume in $1 \mathrm{~s}$. " : defined as $\mathrm{FEV}_{1} /$ forced vital capacity less than the lower limit of normal; ף: included sex, age, BMI, education, smoking status, pack-years and asthma; ${ }^{+}$: further adjusted for $\mathrm{FEV}_{1} \%$ predicted. ${ }^{*}: p<0.05 ; * * *: p<0.001$.
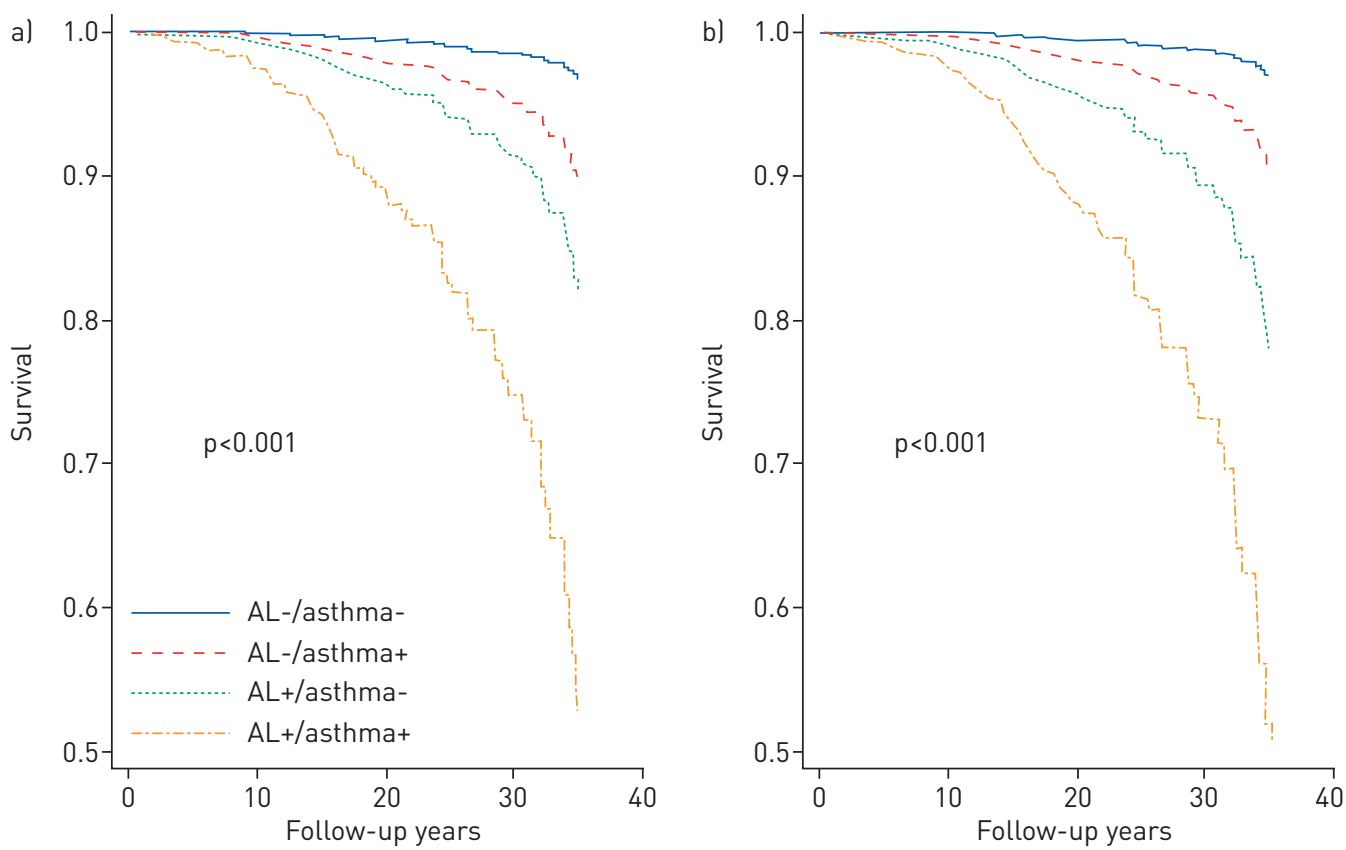

FIGURE 1 Survival curves for mortality by chronic obstructive pulmonary disease across the four airflow limitation (AL)/asthma groups based on Cox proportional hazards models adjusted for sex, age, body mass index, education, smoking status and pack-years. a) Survival curves for the four groups based on airflow limitation defined as forced expiratory volume in $1 \mathrm{~s}\left(\mathrm{FEV}_{1}\right)$ /forced vital capacity $(\mathrm{FVC})<70 \%$. b) Survival curves for the four groups based on airflow limitation defined as $\mathrm{FEV} 1 / \mathrm{FVC}$ less than the lower limit of normal.

to subjects with moderate-to-severe COPD at baseline [34]. Secondly, in our study only one-third of the subjects with airflow limitation in the general population had been seen by a doctor for COPD and this group had baseline FEV1 levels that were $>30 \%$ lower than those of subjects with airflow limitation but no 
COPD diagnosis (data not shown). Finally, we did not find different mortality risks associated with asthma when analyses were restricted to subjects with low lung function levels (i.e. FEV $1<80 \%$ predicted) at baseline.

In line with these observations is our finding that the increased mortality rates observed in asthmatic subjects with airflow limitation were largely mediated by their decreased lung function because adjustment for baseline FEV1 levels reduced the effects of asthma on mortality risk by $>50 \%$ among subjects with airflow limitation. In addition, the excess mortality risk associated with asthma was mainly accounted for by death events that listed COPD as the underlying cause of death, even though these cause-specific analyses should be interpreted with caution because of the relatively small sample size.

It has previously been reported [5] that, in the TESAOD cohort, subjects who developed persistent airflow limitation in association with asthma and those who developed airflow limitation without asthma showed different profiles of risk factors, with the main risk factor being eosinophilia for the former and smoking for the latter. They also had different trajectories of lung function, with lung function impairment largely related to early adulthood deficits in the group with asthma and to accelerated decline of lung function throughout adult life in the group without asthma. Whether and how these differences are related to the different mortality risks of these two groups remains to be determined. Also, our study did not specifically address clinical differences at baseline between asthmatics with and without airflow limitation that may, in turn, be related to their different mortality risks. It is conceivable that the former are more likely to have more severe and persistent forms of asthma, but this hypothesis should be addressed in prospective studies, ideally starting from childhood or young adult age. Finally, in the TESAOD cohort no bronchodilator test was completed at baseline and, therefore, we do not know whether our findings would have been any different if the four groups were defined using post-bronchodilator $\mathrm{FEV} 1 / \mathrm{FVC}$ values as recommended by the Global Initiative for Chronic Obstructive Lung Disease guidelines [4]. Among the strengths of our study are the population-based nature of the TESAOD cohort, the availability of objectively assessed airflow limitation both based on fixed and LLN cut-offs of FEV1/FVC, and the nearly 40-year long mortality follow-up.

In conclusion, in a sample of the general adult population we found subjects with the concomitant presence of airflow limitation and a diagnosis of asthma to be at increased risk of dying during follow-up and these effects to be mainly related to their baseline lung function deficits.

\section{References}

1 Soriano JB, Davis KJ, Coleman B, et al. The proportional venn diagram of obstructive lung disease: two approximations from the United States and the United Kingdom. Chest 2003; 124: 474-481.

2 Viegi G, Matteelli G, Angino A, et al. The proportional venn diagram of obstructive lung disease in the Italian general population. Chest 2004; 126: 1093-1101.

3 Guerra S, Martinez FD. Epidemiology of the origins of airflow limitation in asthma. Proc Am Thorac Soc 2009; 6: $707-711$.

4 Vestbo J, Hurd SS, Agusti AG, et al. Global strategy for the diagnosis, management, and prevention of chronic obstructive pulmonary disease: GOLD executive summary. Am J Respir Crit Care Med 2013; 187: 347-365.

5 Guerra S, Sherrill DL, Kurzius-Spencer M, et al. The course of persistent airflow limitation in subjects with and without asthma. Respir Med 2008; 102: 1473-1482.

6 Marsh SE, Travers J, Weatherall M, et al. Proportional classifications of COPD phenotypes. Thorax 2008; 63: 761-767.

7 Piras B, Miravitlles M. The overlap phenotype: the (missing) link between asthma and COPD. Multidiscip Respir Med 2012; 7: 8.

8 Gibson PG, Simpson JL. The overlap syndrome of asthma and COPD: what are its features and how important is it?. Thorax 2009; 64: 728-735.

9 Shaya FT, Dongyi D, Akazawa MO, et al. Burden of concomitant asthma and COPD in a Medicaid population. Chest 2008; 134: 14-19.

10 Blanchette CM, Gutierrez B, Ory C, et al. Economic burden in direct costs of concomitant chronic obstructive pulmonary disease and asthma in a Medicare advantage population. J Manag Care Pharm 2008; 14: $176-185$.

11 Blanchette CM, Broder M, Ory C, et al. Cost and utilization of COPD and asthma among insured adults in the US. Curr Med Res Opin 2009; 25: 1385-1392.

12 Weatherall M, Travers J, Shirtcliffe PM, et al. Distinct clinical phenotypes of airways disease defined by cluster analysis. Eur Respir J 2009; 34: 812-818.

13 Hardin M, Silverman EK, Barr RG, et al. The clinical features of the overlap between COPD and asthma. Respir Res 2011; 12: 127.

14 Seemungal TA, Donaldson GC, Paul EA, et al. Effect of exacerbation on quality of life in patients with chronic obstructive pulmonary disease. Am J Respir Crit Care Med 1998; 157: 1418-1422.

15 Soler-Cataluna JJ, Martinez-Garcia MA, Roman Sanchez P, et al. Severe acute exacerbations and mortality in patients with chronic obstructive pulmonary disease. Thorax 2005; 60: 925-931.

16 Hospers JJ, Schouten JP, Weiss ST, et al. Asthma attacks with eosinophilia predict mortality from chronic obstructive pulmonary disease in a general population sample. Am J Respir Crit Care Med 1999; 160: $1869-1874$.

17 Hospers JJ, Postma DS, Rijcken B, et al. Histamine airway hyper-responsiveness and mortality from chronic obstructive pulmonary disease: a cohort study. Lancet 2000; 356: 1313-1317. 
18 Silverstein MD, Reed CE, O'Connell EJ, et al. Long-term survival of a cohort of community residents with asthma. N Engl J Med 1994; 331: 1537-1541.

19 Lange P, Ulrik CS, Vestbo J. Mortality in adults with self-reported asthma. Copenhagen City Heart Study Group. Lancet 1996; 347: 1285-1289.

20 Ulrik CS, Frederiksen J. Mortality and markers of risk of asthma death among 1,075 outpatients with asthma. Chest 1995; 108: 10-15.

21 Panizza JA, James AL, Ryan G, et al. Mortality and airflow obstruction in asthma: a 17-year follow-up study. Intern Med J 2006; 36: 773-780.

22 Diaz-Guzman E, Khosravi M, Mannino DM. Asthma, chronic obstructive pulmonary disease, and mortality in the U.S. Population. COPD 2011; 8: 400-407.

23 Soriano JB, Vestbo J, Pride NB, et al. Survival in COPD patients after regular use of fluticasone propionate and salmeterol in general practice. Eur Respir J 2002; 20: 819-825.

24 Mapel DW, Nelson LS, Lydick E, et al. Survival among COPD patients using fluticasone/salmeterol in combination versus other inhaled steroids and bronchodilators alone. COPD 2007; 4: 127-134.

25 Mapel DW, Hurley JS, Roblin D, et al. Survival of COPD patients using inhaled corticosteroids and long-acting $\beta$-agonists. Respir Med 2006; 100: 595-609.

26 McGhan R, Radcliff T, Fish R, et al. Predictors of rehospitalization and death after a severe exacerbation of COPD. Chest 2007; 132: 1748-1755.

27 Lebowitz MD, Knudson RJ, Burrows B. Tucson epidemiologic study of obstructive lung diseases. I: methodology and prevalence of disease. Am J Epidemiol 1975; 102: 137-152.

28 Knudson RJ, Slatin RC, Lebowitz MD, et al. The maximal expiratory flow-volume curve. Normal standards, variability, and effects of age. Am Rev Respir Dis 1976; 113: 587-600.

29 Davis KB, Fisher L, Gillespie MJ, et al. A test of the national death index using the coronary artery surgery study (CASS). Control Clin Trials 1985; 6: 179-191.

30 Knudson RJ, Lebowitz MD, Holberg CJ, et al. Changes in the normal maximal expiratory flow-volume curve with growth and aging. Am Rev Respir Dis 1983; 127: 725-734.

31 Hankinson JL, Odencrantz JR, Fedan KB. Spirometric reference values from a sample of the general U.S. Population. Am J Respir Crit Care Med 1999; 159: 179-187.

32 Andersen PK, Geskus RB, de Witte T, et al. Competing risks in epidemiology: possibilities and pitfalls. Int $J$ Epidemiol 2012; 41: 861-870.

33 Huovinen E, Kaprio J, Vesterinen E, et al. Mortality of adults with asthma: a prospective cohort study. Thorax 1997; 52: 49-54.

34 Burrows B, Bloom JW, Traver GA, et al. The course and prognosis of different forms of chronic airways obstruction in a sample from the general population. N Engl J Med 1987; 317: 1309-1314. 